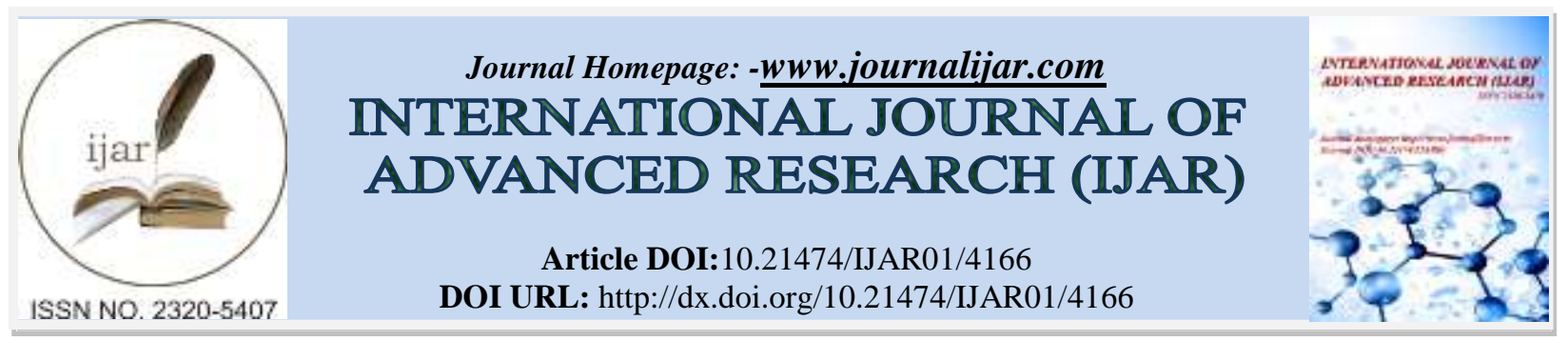

RESEARCH ARTICLE

\title{
CLINICAL AND MRI ASSESSMENT OF THE PAROTID GLAND IN DIABETIC PATIENTS: PRELIMINARY STUDY.
}

\author{
Ola Mohamed Rehan MSc ${ }^{1}$, Hoda Abdel Kader Saleh $\mathrm{PhD}^{2}$, Dr. Ayman Ismail Kamel $\mathrm{PhD}^{3}$ and Noha Saleh \\ Abu Taleb $\mathrm{PhD}^{4}$. \\ 1. Assistant Lecturer of Oral and Maxillofacial Radiology, Faculty of Oral and Dental Medicine, Cairo University. \\ 2. Professor of Oral and Maxillofacial Radiology, Faculty of Oral and Dental Medicine, Cairo University. \\ 3. Professor of Radiology, Faculty of Medicine, Cairo University \\ 4. Assoc. Professor of Oral and Maxillofacial Radiology, Faculty of Oral and Dental Medicine, Cairo University.
}

\section{Manuscript Info}

Manuscript History

Received: 16 March 2017

Final Accepted: 12 April 2017

Published: May 2017

Key words:-

Diabetes Mellitus; Magnetic Resonance

Imaging; Magnetic Resonance

Sialography ; Sialometry

\section{Abstract}

Objective: To assess the parotid gland in diabetic patients clinically and by using magnetic resonance imaging.

Methods: 20 subjects (10 volunteers and 10 diabetic patients) were examined clinically to detect the presence of xerostomia and bad oral hygiene. Salivary flow rate then, was measured for all subjects to assess the gland function. Finally, axial and coronal MR-T1WIs were acquired followed by MR sialography for the left parotid gland.

Results: The diabetic group showed statistically significant higher prevalence of xerostomia and bad oral hygiene than the control group ( $P$-value $=0.001 ; 0.006$ respectively). The salivary flow rate of the control group showed statistically significant higher mean values in both the pre- and post-stimulation states $(P$-values $=0.027 ; 0.001$ respectively) than the diabetic group. The ductal changes in the diabetic group showed statistically significant higher prevalence of ductal changes than the control group $(P$-value $=0.025)$. As well, the diabetic group showed statistically significant higher prevalence of enlargement $(P$-value $=0.001)$ and statistically significant higher prevalence of parenchymal changes $(P$-value $=0.019)$ than the control group

Conclusion Diabetes mellitus may cause the hypofunction of the salivary glands and the MRI and MR sialography may be valuable techniques in the examination of the structure and ductal morphology of the salivary glands of diabetic patients.

Copy Right, IJAR, 2016,. All rights reserved.

\section{Introduction:-}

Diabetes mellitus (DM) is a metabolic syndrome characterized by hyperglycemia and instability in the metabolism of carbohydrates, proteins, and lipids (Wang et al., 2017). It results from relative or absolute insulin deficiency. Absolute insulin deficiency is caused by the impairment of its biosynthesis and excretion of pancreatic islets by beta cells (type I), while relative insulin deficiency results from the impairment of the reaction of cell, tissue and peripheral organs to insulin activity (type II) (Malicka et al. 2014; Wang et al., 2017). 
The oral complications of diabetes mellitus may include periodontal disease and gingival inflammation, dental caries, mucosal lesions, and xerostomia (Bissong et al., 2015).

There are various radiographic techniques used for evaluation of the salivary gland structure such as magnetic resonance imaging (MRI), computed tomography (CT), ultrasonography, and scintigraphy. On the other hand, the ductal system can be evaluated by conventional sialography and recently magnetic resonance (MR) sialography (Kuan et al., 2016).

MRI has several advantages over other diagnostic imaging procedures. It has extremely high contrast resolution between soft tissues. Furthermore, in MRI no ionizing radiation is involved, and therefore do not have the associated harmful effects of ionizing radiation (White and Pharoah, 2014). Advantages of MR sialography are rapid acquisition times, noninvasiveness, and the possibility to visualize all major salivary glands without further positioning of the patient (Kalinowski et al., 2002).

There are various clinical and radiographic techniques used for evaluation of the salivary gland excretory function. The most advocated clinical method for diagnosing salivary gland dysfunction is to quantitate unstimulated and stimulated whole saliva flow rates (SFR) (Diogo Löfgren et al., 2012).

The aim of this study is the evaluation of the parotid gland structure, ductal system, and function in diabetic patients.

\section{Patients And Methods:-}

Twenty subjects were selected from the outpatient clinic of the Oral Medicine and Diagnosis Department, Faculty of Oral and Dental Medicine, Cairo university. The subjects selected were divided into two groups; ten healthy volunteers (control group) and ten patients with type 2 diabetes mellitus.

Volunteer subjects were selected according to the following criteria, no parotid gland diseases as verified by the history, the clinical examination, and the acquired T1WIs. Also, they were not under any medication for any other disorder or suffering of any systemic disease which may affects salivary gland function. Diabetic subjects did not take any medications except those for diabetic treatment.

A written informed consent was obtained from all the subjects sharing in this study. The subjects were examined clinically for the presence of xerostomia and bad oral hygiene. Next, the salivary flow rate (SFR) was measured for each subject 2 hours after breakfast at $11 \mathrm{am}$. The subject spitted in a cup and saliva was collected for 5 minutes. Then, the gland was stimulated by $5 \mathrm{ml}$ lemon juice and the post stimulation saliva was collected for 5 minutes in another cup. The collected saliva was measured by plastic syringe in units of $\mathrm{ml} / \mathrm{min}$.

MRI examination of left parotid gland for each patient was performed by using a $1.5 \mathrm{~T}$ superconductive magnet. The examination was performed at the Radiology Department, Faculty of Medicine, Cairo University. Axial T1WIs were performed using head coil with the following parameters (TSE sequence; TR: 488; TE: 15; NEX: 2; FOV: 230 mm; Image matrix: $232 \times 185$; Slice thickness: $4 \mathrm{~mm}$; Interslice gap: $5 \mathrm{~mm}$; Acquisition time: 2 minutes and 28 seconds). Coronal T1WIs were performed using head coil with the following parameters (TSE sequence; TR: 488; TE: 15; NEX: 2; FOV: $230 \mathrm{~mm}$; Image matrix: 232× 185; Slice thickness: $3 \mathrm{~mm}$; Interslice gap: $3 \mathrm{~mm}$; Acquisition time: 2 minutes and 15 seconds).

MR sialography was performed after stimulation of the gland by $5 \mathrm{ml}$ lemon juice to evaluate the ductal morphology, using single shot turbo spin echo sequence (SSTSE) and surface coil with the following parameters (TR: 8000; TE: 900; NEX: 2; FOV: $120 \mathrm{~mm}$; Image matrix: 124×150; Slice thickness: $30 \mathrm{~mm}$; Acquisition time: 16 seconds)

\section{Statistical Analysis:-}

Student's t-test and Mann-Whitney U test were used for comparisons between the two groups. Chi-square $\left(\mathrm{x}^{2}\right)$ test was used for studying the comparisons and associations between different qualitative variables. Pearson's correlation coefficient was used to determine significant correlations between different quantitative variables. The significance level was set at $\mathrm{P} \leq 0.05$. Statistical analysis was performed with $\mathrm{IBM}^{\circledR}$ (Corporation, NY, USA). SPSS $^{\circledast}$ (Inc., an IBM Company). Statistics Version 20 for Windows. 


\section{Results:-}

Regarding the clinical findings, the diabetic group showed statistically significant higher prevalence of xerostomia than the control group $(P$-value $=0.001)$.

Similarly, the oral hygiene, the diabetic group showed statistically significant higher prevalence of bad oral hygiene than the control group $(P$-value $=0.006)$. Besides, the salivary flow rate $(\mathrm{SFR})$ of the control group showed statistically significant higher mean values in both the pre- and post-stimulation states $(P$-values $=0.027$ and 0.001 respectively) than the diabetic group.

Concerning the imaging results, the ductal changes in the diabetic group showed statistically significant higher prevalence than the control group $(P$-value $=0.025)($ Fig1 $)$.

As well, the diabetic group showed statistically significant higher prevalence of enlargement $(P$-value $=0.001)$ (Fig2) and statistically significant higher prevalence of parenchymal changes $(P$-value $=0.019)$ than the control group (Fig3).

A correlation was found between SFR values and the occurrence of xerostomia in the diabetic group. Patients with no xerostomia showed statistically significant higher mean SFR than patients with xerostomia $(P$-value $=0.044)$.

Table 1:- The frequency, percentages, and $P$-value of comparison between xerostomia in the two studied groups.

\begin{tabular}{|l|c|c|c|c|c|}
\hline \multirow{2}{*}{$\begin{array}{c}\text { Group } \\
\text { Xerostomia }\end{array}$} & \multicolumn{2}{|c|}{ Control group } & \multicolumn{2}{c|}{ Diabetic group } & \multirow{2}{*}{$P$-value } \\
\cline { 2 - 5 } Xerostomia & Frequency & $\%$ & Frequency & $\%$ & \\
\hline No Xerostomia & 0 & 0 & 7 & 70 & \multirow{2}{*}{$0.001^{*}$} \\
\hline
\end{tabular}

*: Significant at $P \leq 0.05$

Table 2:-The frequency, percentages, and $P$-value of comparison between oral health status in the two studied groups.

\begin{tabular}{|c|c|c|c|c|c|}
\hline Group & \multicolumn{2}{|c|}{ Control group } & \multicolumn{2}{|c|}{ Diabetic group } & \multirow{2}{*}{$P$-value } \\
\cline { 2 - 5 } Oral health & Frequency & $\%$ & Frequency & $\%$ & \\
\hline Good & 9 & 90 & 3 & 30 & \multirow{2}{*}{$0.006^{*}$} \\
\hline Bad & 1 & 10 & 7 & 70 & \\
\hline
\end{tabular}

*: Significant at $P \leq 0.05$

Table 3:- The mean and standard deviation (SD) values, and $P$-value of comparisons between SFR in the two studied groups.

\begin{tabular}{|c|c|c|c|c|c|}
\hline \multirow{2}{*}{ Geriod } & \multicolumn{2}{|c|}{$\begin{array}{c}\text { Control } \\
\text { group }\end{array}$} & \multicolumn{2}{c|}{$\begin{array}{c}\text { Diabetic } \\
\text { group }\end{array}$} & \multirow{2}{*}{$\begin{array}{c}\text {-value } \\
\end{array}$} \\
\cline { 2 - 5 } & $\begin{array}{c}\text { Mean } \\
(\mathrm{ml} / \mathrm{min})\end{array}$ & SD & $\begin{array}{c}\text { Mean } \\
(\mathrm{ml} / \mathrm{min})\end{array}$ & SD & \\
\hline Pre-stimulation & 0.39 & 0.10 & 0.30 & 0.07 & $0.027^{*}$ \\
\hline Post-stimulation & 2.75 & 0.53 & 1.65 & 0.53 & $0.001^{*}$ \\
\hline
\end{tabular}

*: Significant at $P \leq 0.05$

Table 4:- The frequency, percentages, and P-value of comparisons between ductal changes in the two studied groups revealed in MR sialography.

\begin{tabular}{|l|c|c|c|c|c|}
\hline \multirow{2}{*}{\begin{tabular}{|c|c|} 
Group \\
Ductal changes
\end{tabular}} & \multicolumn{2}{|c|}{ Control group } & \multicolumn{2}{c|}{ Diabetic group } & \multirow{2}{*}{$P$-value } \\
\cline { 2 - 5 } & Frequency & $\%$ & Frequency & $\%$ & \\
\hline Ductal changes & 0 & 0 & 4 & 40 & \multirow{2}{*}{$0.025^{*}$} \\
\hline No Ductal changes & 10 & 100 & 6 & 60 & \\
\hline
\end{tabular}

*: Significant at $P \leq 0.05$ 
Table 5:- The frequency, percentages, and $P$-value of comparisons between enlargement in the two studied groups revealed in the MR images.

\begin{tabular}{|c|c|c|c|c|c|}
\hline Group & \multicolumn{2}{|c|}{ Control group } & \multicolumn{2}{|c|}{ Diabetic group } & \multirow{2}{*}{$P$-value } \\
\cline { 2 - 5 } Enlargement & Frequency & $\%$ & Frequency & $\%$ & \\
\hline Enlargement & 0 & 0 & 7 & 70 & \multirow{2}{*}{$0.001^{*}$} \\
\hline No Enlargement & 10 & 100 & 3 & 30 & \\
\hline
\end{tabular}

*: Significant at $P \leq 0.05$

Table 6:- The frequency, percentages, and $P$-value of comparison between parenchymal changes in the two studied groups revealed in the MR images.

\begin{tabular}{|l|c|c|c|c|c|}
\hline \multicolumn{1}{c|}{ Group } & \multicolumn{2}{c|}{ Control group } & \multicolumn{2}{c|}{ Diabetic group } & \multicolumn{2}{c|}{$P$-value } \\
\cline { 2 - 6 } \multicolumn{1}{c|}{ Parenchymal changes } & Frequency & $\%$ & Frequency & $\%$ & \\
\hline Parenchymal changes & 1 & 10 & 6 & 60 & $0.019 *$ \\
\hline No Parenchymal changes & 9 & 90 & 4 & 40 & \\
\hline
\end{tabular}

*: Significant at $P \leq 0.05$
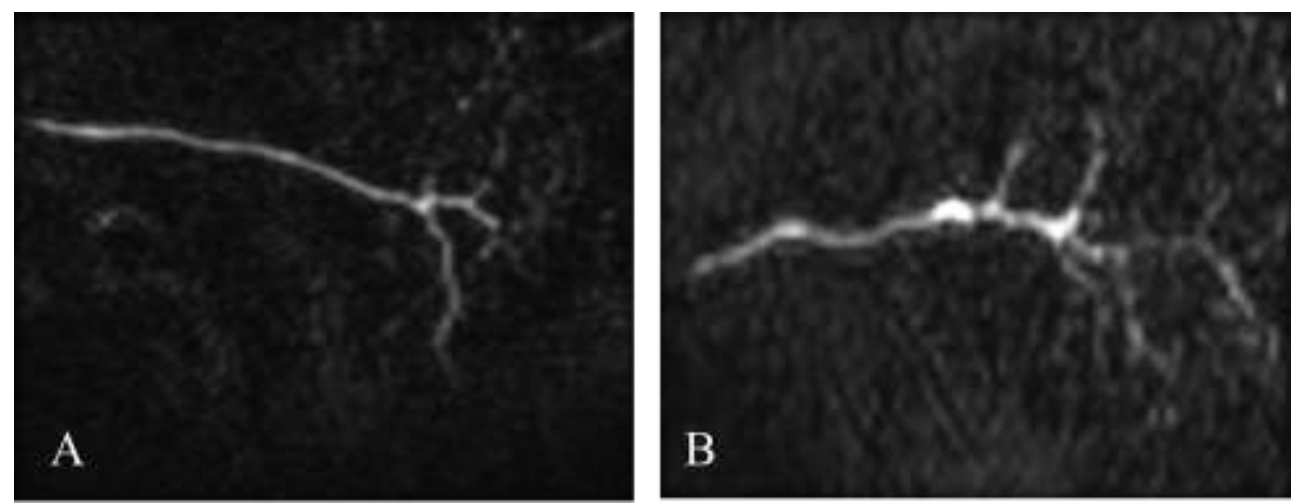

Fig 1:- MR sialography of the left parotid glands of normal subject A) showing the main duct and intraglandular ducts; B) of diabetic patient showing the ductal changes in the form of dilatation and sausage shape in the main duct and intraglandular ducts.
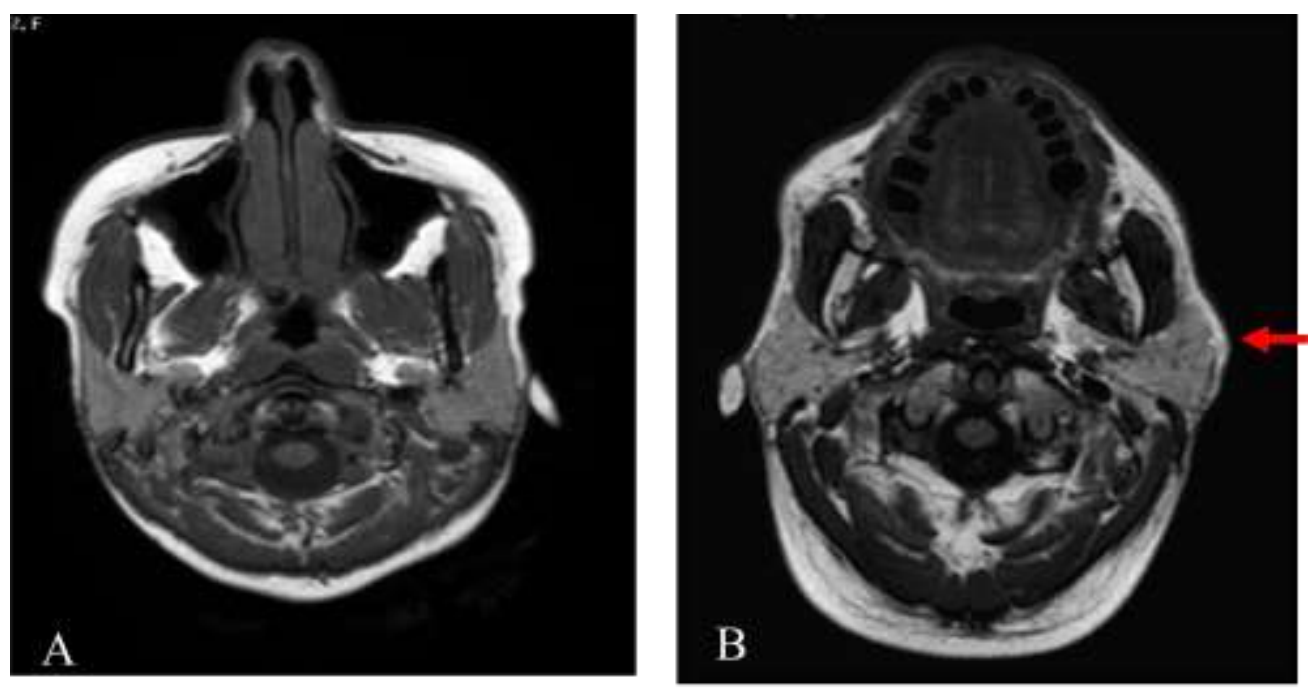

Fig 2:- Axial T1WIs showing parotid glands of normal (A) and diabetic patient (B). Note enlargement of the left parotid gland in the diabetic patient (arrow). 


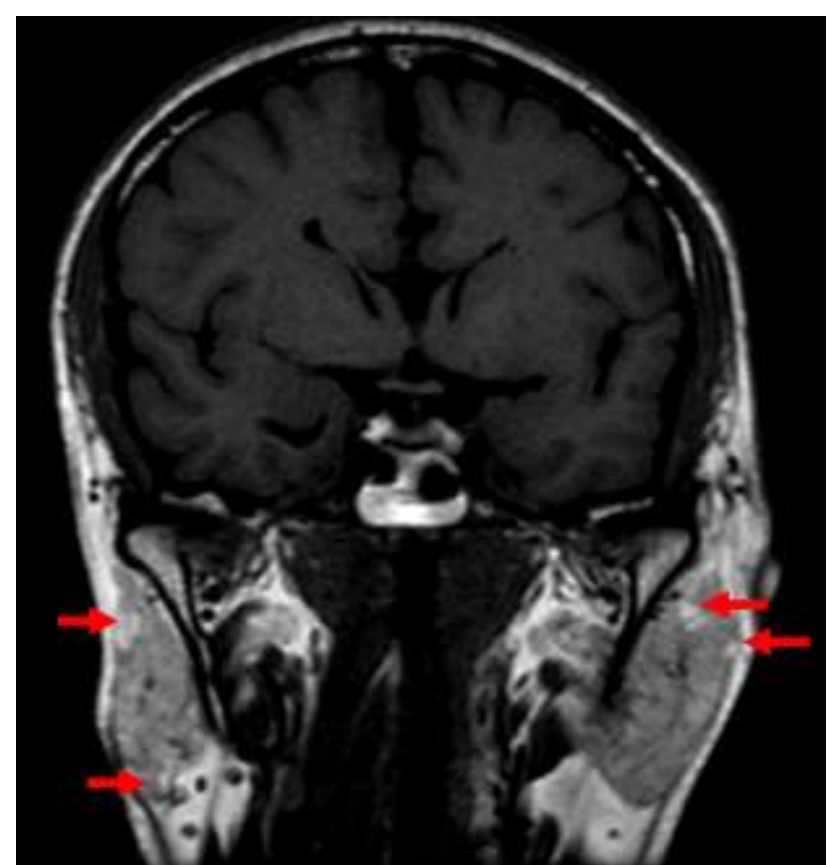

Fig 3:- Coronal T1WIs showing parenchymal changes (areas of increased signal intensity inside the parotid parenchyma) of the right and left parotid glands (arrows).

\section{Discussion:-}

Diabetes mellitus is a complex metabolic disease described by altered carbohydrate, lipid, and protein metabolism resulting in marked or absolute insulin deficiency or peripheral tissue insulin resistance (Vernillo, 2001).

The oral manifestations of diabetes mellitus include increased accumulation of plaque, higher susceptibility to infections, and pronounced hyperplasia of the attached gingival. All play a significant role in the increased incidence of periodontal disease, oral candidal infections, dental caries, dysgeusia or altered taste, and burning mouth syndrome. Moreover, diffuse non-tender bilateral enlargement of the parotid glands, called diabetic sialosis, may be noted in both types of diabetes. Furthermore, xerostomia may result from an overall diminished flow of saliva (Islam, 2011).

There are various techniques for the evaluation of the salivary gland morphology and function and in this study the parotid glands of diabetic patients were examined using MRI.

Twenty subjects, ten healthy volunteers and ten type 2 diabetic patients were selected for the study. Each subject was asked for the presence of xerostomia. For each subject, pre and post stimulation SFR of the parotid gland was measured by $5 \mathrm{ml}$ of lemon juice. Afterward, axial T1WIs and MR sialography were performed to evaluate the parenchyma and the ductal system of the gland respectively. In the present study, the left parotid gland was selected for the MRI examinations for standardization.

MR sialography imaging was performed using fast and high resolution SSTSE sequence and a small surface coil is placed on the parotid gland area to obtain high resolution MR sialographic images Takagi et al, 2005).

A single section with a thick imaging slab was performed to obtain a two dimensional image of the curvilinear fluid filled duct similar to conventional radiographs using x-rays. MR sialography examination was performed after the stimulation of the gland by lemon juice to enhance the visibility of the main and branching ducts (Hugill et al., 2008).

Clinical results of this study revealed that the diabetic group had statistically significant $(P=0.001)$ higher prevalence of xerostomia than the control group ( $70 \%$ and $0 \%$ respectively). This finding was parallel to Carda et 
al., 2006; Sandberg and Wikblad, 2003; Khovidhunkit et al., 2009 and Malicka et al., 2014 who found that type 2 diabetic patients showed subjective complaint of xerostomia more than healthy controls. However, Vasconcelos et al., 2010 found in his study that there was no statistically significant difference between type 2 diabetic patients and non diabetic subjects.

In the current study the diabetic group showed statistically significant $(P=0.006)$ higher prevalence of bad oral health than the control group (70\% and $10 \%$ respectively) and this finding was close to Campus et al 2005 . It is well known that patients with diabetes are liable to oral infections that lead to caries, periodontal disorders, and tooth loss due to the poor glycemic control in diabetics (Campus et al., 2005; Taylor and Borgnakke, 2008).

Regarding SFR, the mean unstimulated SFR in the diabetic group was significantly $(P=0.027)$ lower than that in the normal group $(0.30 \mathrm{ml} / \mathrm{min}$ and $0.39 \mathrm{ml} / \mathrm{min}$ respectively). Similarly, the mean stimulated SFR in the diabetic group was also significantly $(P=0.001)$ lower than that in the control group $(1.65 \mathrm{ml} / \mathrm{min}$ and $2.75 \mathrm{ml} / \mathrm{min}$ respectively).

Similar to the results of this study Dodds et al., 2000; Lin et al., 2002; Mata et al., 2004; Montaldo et al., 2010; Malicka et al., 2014 when studied the effect of diabetes mellitus on the salivary function, they found that the resting and stimulated SFR of the diabetic subjects were consistently lower than those of healthy.

Furthermore, Chávez et al., 2001 examined the SFR in controlled and uncontrolled type 2 diabetic patients and healthy controls. They found that adults with poorly controlled diabetes might have impaired salivary flow in comparison with subjects with better controlled diabetes and non diabetic subjects, yet they may not have concomitant xerostomic complaints.

The impairment of the parotid gland function may be multifactorial. Fatty infiltration or accumulation within parenchymal portion of the gland (Panchbhai et al., 2010). Other theory suggested that salivary hypofunction and xerostomia may be due to diabetic neuropathy and atrophy of the myoepithelial cells, both interfere with the secretion mechanism which is produced by the stimulation of the alpha and beta adrenergic receptors of the acinar cells that physiologically induce exocytosis (Carda et al., 2006).

Moreover, the hypofunction was also attributed to polydipsia and polyuria which reduce the extracellular fluid that directly affects the salivary production (Panchbhai et al., 2010).

About the ductal changes observed in this study, the diabetic group showed statistically significant $(P=0.025)$ higher prevalence of ductal changes in the form of dilatation and other signs of inflammation than control group (40\% and $0 \%$ respectively).

Diabetic patients are more susceptible to developing oral bacterial infections as they are well known to have an impaired defense mechanism hence considered to be immuno-compromised. Subsequently, retrograde infections may affect the salivary glands especially that cleansing and buffering capacity of the saliva is diminished in those patients (Panchbhai et al., 2010; Al-Maskari et al., 2011).

Pertaining to the MRI findings in the T1WI, left parotid gland enlargement was observed in $70 \%$ of the diabetic patients versus $0 \%$ in the control group this parallel to the clinical finding. Moreover, parenchymal changes in the form of high signal intensity areas scattered within the gland parenchyma was observed in $60 \%$ of the diabetic patients versus $10 \%$ in the control group, the prevalence of these parenchymal changes between both groups was statistically significant $(P=0.019)$.

Diabetes mellitus is one of the major etiological causes of sialosis, a pathology generally characterized by a painless bilateral enlargement of the parotid gland (Carda et al., 2006; Chen et al., 2013).

In many studies, the parotid gland enlargement found in diabetic patients was attributed to either a secondary increase of the adipose tissue within the parenchymal portion of the gland or together with the presence of numerous intra-cytoplasmatic fat inclusions in both the acinar and ductal cells of the parotid glands which are caused by modifications in the diabetic fat metabolism (Carda et al., 2006; Carda et al., 2005). Furthermore, the glandular enlargement in diabetics may be the result of acinar hypertrophy and this was also approved by Scully et al., 2008. 
On the other hand, Carda et al., 2005 stated that in parotid sialosis of diabetic origin, the parotid enlargement may be due to the fatty infiltration in glandular stroma only as they observed that the glands had smaller acini than controls and had ductal dilatation with stasis of secretory material.

Dependent on the previous studies, the high signal intensity areas observed in the diabetic patients in this study may be due to fat deposition in the parotid parenchyma.

In the present study, a correlation was found between the unstimulated SFR and the presence of xerostomia in diabetic patients where the xerostomic patients showed statistically significant lower mean unstimulated SFR than non xerostomic ones.

\section{Conclusion:-}

Diabetes mellitus may cause the hypofunction of the salivary glands and the MRI and MR sialography are valuable techniques in the examination of the structure and ductal morphology of the salivary glands.

1. Diabetes mellitus may cause the hypofunction of the salivary glands and the MRI and MR sialography are valuable techniques in the examination of the structure and ductal morphology of the salivary glands.

2. Wang B, Du J, Zhu Z, Ma Z, Wang S, Shan Z. (2017): Evaluation of Parotid Salivary Glucose Level for Clinical Diagnosis and Monitoring Type 2 Diabetes Mellitus Patients. Biomed Res Int., 1-5.

3. Malicka B, Kaczmarek U, Skokiewicz-Malinowska K. (2014): Prevalence of xerostomia and the salivary flow rate in diabetic patients. Adv Clin Exp Med., 23(2):225-33.

4. Bissong MEA, Azodo CC, Agbor MA, Fon PN, Bissong M, Azodo CC, Agbor AM , Nkuo- Akenji T , Nde F . (2015): Oral health Status of diabetic patients in South West. Oral health status of diabetes mellitus patients in Southwest Cameroon.

5. Kuan EC, Mallen-St. Clair J, St. John MA. (2016): Evaluation of Parotid Lesions. Otolaryngol Clin North Am., 49(2):313-25.

6. White SC, Pharoah MJ. (2014): Oral Radiology principles and interpretation ( $7^{\text {th }}$ edn). Canada El Sevier Mosby.

7. Kalinowski M, Heverhagen JT, Rehberg E, Klose KJ, Wagner HJ. (2002): Comparative study of MR sialography and digital subtraction sialography for benign salivary gland disorders. Am J Neuroradiol., 23(9):1485-92.

8. Diogo Löfgren C, Wickström C, Sonesson M, Tapia Lagunas P, Christersson C. (2012): A systematic review of methods to diagnose oral dryness and salivary gland function. BMC Oral Health., 12(1):29.

9. Vernillo AT. (2001): Diabetes mellitus: Relevance to dental treatment. Oral Surg Oral Med Oral Pathol Oral Radiol Endod. 91(3):263-70.

10. Islam NM, Bhattacharyya I, Cohen DM. (2011): Common oral manifestations of systemic disease. Otolaryngol Clin North Am., 44(1):161-82.

11. Takagi Y, Sumi M, Van Cauteren M, Nakamura T. (2005): Fast and high-resolution MR sialography using a small surface coil. J Magn Reson Imaging., 22(1):29-37.

12. Hugill J, Sala E, Hollingsworth KG, Lomas DJ. (2008): MR sialography: The effect of a sialogogue and ductal occlusion in volunteers. Br J Radiol., 81(967):583-6.

13. Carda C, Mosquera-Lloreda N, Salom L, Gomez De Ferraris ME, Peydró A, Carda DC. (2006): Structural and functional salivary disorders in type 2 diabetic patients. Med Oral Patol Oral Cir Bucal., 11:309-14.

14. Sandberg GE, Wikblad KF. (2003): Oral dryness and peripheral neuropathy in subjects with type 2 diabetes. J Diabetes Complications., 17(4):192-8.

15. Khovidhunkit SPS, Suwantuntula T, Thaweboon S, Mitrirattanakul S, Chomkhakhai U, Khovidhunkit W, et al. (2009): Preliminary Report Xerostomia , Hyposalivation, and Oral Microbiota in Type 2 Diabetic Patients : A Preliminary Study. J Med Assoc Thai., 92(9):1220-8.

16. Vasconcelos ACU, Soares MSM, Almeida PC, Soares TC. (2010): Comparative study of the concentration of salivary and blood glucose in type 2 diabetic patients. J Oral Sci.,52(2):293-8.

17. Campus G, Salem A, Uzzau S, Baldoni E, Tonolo G. (2005): Diabetes and periodontal disease: a case-control study. J Periodontol., 76(3):418-25.

18. Taylor GW, Borgnakke WS. (2008): Periodontal disease: Associations with diabetes, glycemic control and complications. Oral Dis., 14(3):191-203.

19. Dodds MW, Yeh CK, Johnson DA. (2000): Salivary alterations in type 2 (non-insulin-dependent) diabetes 
mellitus and hypertension. Community Dent Oral Epidemiol., 28(5):373-81.

20. Lin CC, Sun SS, Kao A, Lee CC. (2002): Impaired salivary function in patients with noninsulin-dependent diabetes mellitus with xerostomia. J Diabetes Complications., 16(2):176-9.

21. Mata AD, Marques D, Rocha S, Francisco H, Santos C, Mesquita MF, et al. Effects of diabetes mellitus on salivary secretion and its composition in the human. Mol Cell Biochem [Internet]. 2004;261(1):137-42. Available from: http://www.scopus.com/inward/record.url?eid=2-s2.03543149684\&partnerID=40\&md5=9d2781d3be599d45d702120d4a09730d\%5Cnhttp://www.embase.com/searc $\mathrm{h} /$ results?subaction=viewrecord\&from=export\&id=L39022414\%5Cnhttp://dx.doi.org/10.1023/B:MCBI.000002 8748.40917.6f

22. Montaldo L, Montaldo P, Papa A, Caramico N, Toro G. (2010): Effects of saliva substitutes on oral status in patients with Type-2 diabetes. Diabet Med., 27(11):1280-3.

23. Chávez EM, Borrell LN, Taylor GW, Ship J a. (2001): A longitudinal analysis of salivary flow in control subjects and older adults with type 2 diabetes. Oral Surg Oral Med Oral Pathol Oral Radiol Endod., 91(2):16673.

24. Panchbhai AS, Degwekar SS, Bhowte RR. (2010): Estimation of salivary glucose, salivary amylase, salivary total protein and salivary flow rate in diabetics in India., 52(3):359-68.

25. Al-Maskari AY, Al-Maskari MY, Al-Sudairy S. (2011): Oral manifestations and complications of diabetes mellitus: A review. Sultan Qaboos Univ Med J., 11(2):179-86.

26. Chen S, Paul BC, Myssiorek D. (2013): An Algorithm Approach to Bilateral Parotid Enlargement Bilateral parotid disease. Otolaryngol - Head Neck Surg., 148(5):732-9.

27. Carda C, Carranza M, Arriaga A, Diaz A, Peydro' A and G mez DF. (2005): Structural differences between alcoholic and diabetic parotid sialosis. Med Oral Patol Oral CirBucal., 10:309-14.

28. Scully C, Bagán J V., Eveson JW, Barnard N, Turner FM. (2008): Sialosis: 35 cases of persistent parotid swelling from two countries. Br J Oral Maxillofac Surg., 46(6):468-72. 